Attendee will realise that Pentecostal churches present a great potential for the management of HIV, and thus remain relevant, to advocate for change among believers attitudes towards miraculous healing and HIVprevention through applying reliable and effective communication models.

Disclosure No significant relationships.

\section{P276 A NATIONAL ACTION PLAN TO ADVANCE THE SEXUAL AND REPRODUCTIVE HEALTH AND RIGHTS OF WOMEN LIVING WITH HIV IN CANADA}

\begin{abstract}
${ }^{1}$ Angela Kaida*, ${ }^{2}$ Tracey Conway, ${ }^{3}$ Wangari Tharao, ${ }^{4}$ Renee Masching, ${ }^{4}$ Jessica Danforth, ${ }^{5}$ Neora Pick, ${ }^{4}$ Valerie Nicholson, ${ }^{6}$ Kerrigan Beaver, ${ }^{3}$ Sandra Godoy, ${ }^{7}$ Rebecca Gormley, ${ }^{6}$ Mina Kazemi, ${ }^{1}$ Sarah Watt, ${ }^{8}$ Ados May, ${ }^{6}$ Mona Loutfy, ${ }^{9}$ Manjulaa Narasimhan. ${ }^{1}$ Simon Fraser University, Faculty of Health Sciences, Burnaby, Canada; ${ }^{2}$ Canadian Positive People Network, Dunrobin, Canada; ${ }^{3}$ Women's Health in Women's Hands Community Health Center, Toronto, Canada; ${ }^{4}$ Canadian Aboriginal AIDS Network, Dartmouth, Canada; ${ }^{5}$ Oak Tree Clinic, BC Women's Hospital, Vancouver, Canada; ${ }^{6}$ Women's College Research Institute, Toronto, Canada; ${ }^{7} B C$ Centre for Excellence in HIVIAIDS, Vancouver, Canada; ${ }^{8}$ Implementing Best Practices Initiative, Washington, USA; ${ }^{9}$ World Health Organization, Geneva, Switzerland
\end{abstract}

\subsection{6/sextrans-2019-sti.401}

Background Action on the World Health Organization (WHO) Global Consolidated Guideline on Sexual and Reproductive Health and Rights (SRHR) of Women Living with HIV (WLWH) recommendations requires evidence-based, equity-oriented, and regionally-specific strategies which are responsive to the priorities and rights of WLWH.

Methods In 2017/18, a team of leading Canadian women's HIV community, research, and service organizations partnered with WHO to convene a webinar series to: define WLWH's SRHR priorities in Canada; disseminate Canadian research and best practices; and highlight the importance of meaningfully engaging WLWH. Webinar topics included: Trauma- and violence-aware practice; Supporting safer HIV disclosure; Reproductive health, rights, and justice; and Resilience, selfefficacy, and peer support (>1,100 webinar views). Subsequent in-person and online consultation with $>130$ key stakeholders identified priorities for a National Action Plan to advance the SRHR of WLWH in Canada.

Results Identified priorities to support SRHR across priority topics focused on transforming enabling environments include: -Incorporate Truth and Reconciliation calls-to-action for Indigenous and non-Indigenous Peoples; • Support WLWH's leadership through equitable, adequately compensated opportunities; - Embed peer support and leadership throughout services for WLWH; •Prioritize women-centred care in service/program delivery, attending to women's diverse priorities, experiences, and identities; -Use inclusive, respectful language to avoid reproducing stigma, discrimination, and marginalization; - Strengthen and expand support for WLWH's extended networks (e.g. parental support); -Implement trauma- and violence-aware practices to ensure safer healthcare spaces; -Improve Knowledge Translation \& Exchange initiatives. Additional topic-specific key messages were identified to inform a National Action Plan.

Conclusion Guided by community engagement, recommendations from the National Action Plan encourage Canada to demonstrate global leadership in advancing SRHR of WLWH by emphasizing the need to create enabling environments for health and healthcare. Implementing the plan is being pursued through planned consultations with provincial and national government representatives and policy-makers.

Disclosure No significant relationships.

\section{P277 REDUCING HIV SELF-TESTING BARRIERS IN BLACK AFRICAN COMMUNITIES USING COLLECT: A PHE HIV INNOVATION FUND PROJECT}

${ }^{1}$ George Halfin, ${ }^{2}$ Will Howells, ${ }^{1}$ Takudzwa Mukiwa, ${ }^{3}$ Dominic Edwardes, ${ }^{4}$ Louise Logan*, ${ }^{1}$ Chamut Kifetew. ${ }^{1}$ Terrence Higgins Trust, Health Improvement, London, UK; ${ }^{2}$ Terrence Higgins Trust, Digital, London, UK; ${ }^{3}$ Terrence Higgins Trust, Digital and Communications, London, UK; ${ }^{4}$ Public Health England, Sexual Health, Reproductive Health and HIV, London, UK

\subsection{6/sextrans-2019-sti.402}

Background Black Africans (BA) are disproportionately affected by HIV in England, comprising 38\% of heterosexuals diagnosed in $2017,57 \%$ of whom were diagnosed late. Late diagnosis was even higher in BA men (69\%).

HIV self-testing is a preferred way to test among BA (Sigma, 2015). Despite increasing online availability of selftests, Terrence Higgins Trust(THT) noted a lower uptake amongst BA than others. One reason provided includes a reluctance to receive kits in shared accommodation.

With public funding, we added Click\&Collect delivery to explore if this would help reduce HIV self-testing barriers.

Methods

- 20,000 self-tests offered online to key communities, including BA, from October-December 2018.

- Click\&Collect option provided, with 4,000+ collection points. While open to all, enhanced promotion went to BA.

- Users were sent two follow-up SMSs requesting results. All those with a reactive result received THT support calls.

- A user survey assessed reasons for using the service.

Results

- 18,597 tests dispatched; 3,291 to BA.

- 50\% BA reported results, compared to 61\% overall.

- Click\&Collect uptake: 10\% overall; 18\% BA men.

- 11 BA reported reactive results, one of whom used Click\&Collect. The reactivity rate for BA was $0.7 \%$. From the user survey:

- Over $48 \%$ of Click\&Collect users stated primary reasons for choosing it were not wanting anyone they lived with accidentally opening package, or finding out they were taking an HIV test.

- $50 \%$ of BA Click\&Collect users chose self-test for confidentiality - compared to 34\% of all other Click\&Collect users, for whom it was not a top reason.

Conclusion Click\&Collect may address privacy/confidentiality issues for BA where this is a primary issue. The proportion of BA men using Click\&Collect was higher than in other groups. As self-testing services increase, Click\&Collect offers a way to increasing HIV testing uptake in a group highly affected by late diagnosis.

Disclosure No significant relationships. 